\title{
EL CUENTO “OLVIDADO" DE JUAN RULFO
}

\author{
POR \\ HARRY L. ROSSER \\ Boston College
}

En su mayoría, los críticos han desconocido la existencia de un brevísimo cuento de Rulfo, identificado en una ocasión por el autor mismo como la primera narrativa que se le publicó: "La vida no es muy seria en sus cosas".

Este cuento apareció por primera vez en una nueva revista literaria, Pan, en Guada1ajara en 1942. Tres años después circuló en un número de América y una vez más en 1978 en El cuento: Revista de imaginación. Desde ese entonces se ha prescindido casi del todo de su existencia, pues nunca se ha incluído el cuento en 1as muchas ediciones de El llano en llamas. Puede que tal omisión haya sido intencional o que se debiera a un desconocimiento general de la existencia de un cuento que Rulfo decidió "olvidar". De hecho, el cuento no volvió a publicarse hasta que se incluyó en la antología persona1 de Rulfo, unos treinta y seis años después de que dichocuento apareció por primera vez. Aun asî, "La vida no es muy seria en sus cosas" no recibió atención crítica. Está ausente en los estudios sistemáticos de Rodríguez Alcalá, Sommers y Durán. Es más, Verdugo y Acker ni siquiera mencionan el texto en sus investigaciones más recientes. Sólo Gordon lo toma en cuenta en el análisis que hizo de la ficción de Rulfo poco antes de que saliera la susodicha antología personal. En los últimos años Leal menciona el cuento, pero muy de paso, en su comprensivo estudio de la obra de Rulfo. En fin, es curioso que se le haya brindado tan poca atención al primer texto de un gran maestro.

Rulfo mismo menospreció "La vida no es muy seria en sus cosas", diciendo que era "del tipo naturalmente que el escritor suele querer olvidar, - lleno de crepúsculos y cosas por el estilo". No obstante, el cuento es indudablemente importante por sus rasgos precursores y por una característica insólita para un cuento rulfiano: la narración tiene como su única protagonista a una mujer. De hecho, este cuento difiere de todos los de El llano en llamas por ser fémino-

\footnotetext{
${ }^{1}$ Se cita el comentario de Rulfo en Carballido, 26.
} 
céntrico. Es decir, es el único cuento que no tiene protagonista masculino ni una perspectiva narrativa atribuida a personajes masculinos. Además, no refleja la actitud rencorosa hacia los personajes femeninos que se sugiere en las relaciones entre los hombres y las mujeres en los otros textos de Rulfo.

En su esencia, "La vida no es muy seria en sus cosas" trata de una viuda atrapada entre el pasado, representado por su esposo difunto, Crispín, y el futuro, encarnado en su hijo que está por nacer. Su profundo sentido de pérdida se mezcla con sus sentimientos maternos de felicidad por la nueva vida que siente latir dentro de ella. Supone que es varón, diciéndole "Crispín" en los pensamientos y en las palabras que le dirige. Sumida en sus pesares, la protagonista anónima siente aumentar un temor para cón la vida de su niño. Se distrae de un confuso presentimiento de tragedia al tratar de pensar en su esposo. Se propone visitar la tumba una tarde, proyectando que esto se hará con la aprobación del niño. $\mathrm{Al}$ treparse a un armario en busca de su abrigo, se resbala y empieza a caerse al duro suelo - un suelo que parecía lejos y sin alcance.

La informalidad del título del cuento y su naturaleza conversacional son típicas del estilo narrativo de Rulfo. La ironía, la economía verbal y la tragedia inevitable que se comunican son rasgos caracterizadores tanto de este cuento como de todos los demás del escritor (i.e. "Es que somos muy pobres", "Diles que no me maten", y "No oyes ladrar los perros".) De hecho, cualquier otra narrativa de Rulfo podría llevar el título del texto que se considera aquí, porque "La vida no es muy seria en sus cosas" sugiere lo que Rufinelli describe como "una suerte de reflexión existencial movida por la compasión hacia los seres humildes y pequeños sin despojarse de amarga ironía" (p.9). En efecto, las cosas van de mal en peor en todo lo que Rulfo escribió.

En la ficción de Rulfo se da por sentada la fijación temática con la muerte. En el cuento de interés aquí, aunque la muerte sea sólo una de las condiciones adversas que la realidad abarca, la protagonista está enajenada de su propia experiencia del presente por un reconocimiento gradual de la muerte que la rodea. Rulfo se atiene al recurso estilístico de la prosopopeya para presentar la realidad de la muerte:

“... ella no se imaginaba a la muerte sino de un modo tranquilo: tal como un río que va creciendo paso a paso, y va empujando las aguas viejas y las cubre lentamente; mas sin precipitarse como lo haría un arroyo nuevo. Asíse imaginaba ella a la muerte, porque más de una vez la vió acercarse (p. 155)".

El uso de la preposición "a" delante de "la muerte", el símil del río, el uso de los adjetivos "viejas" para describir "las aguas" y nuevo con relación a "un arroyo", y la atención a la anáfora en este pasaje sirven todos para recalcar lo personal tanto 
como lo natural de la presencia de la muerte. En una ocasión Rulfo declaró que, igual que sus protagonistas, no le tenía miedo a la muerte: "Nosotros vivimos con la muerte; no puede asustarnos. La convivencia con la muerte está en el carácter mismo de los mexicanos"2.

La perspectiva narrativa del texto es, a primera vista, la de la tercera persona tradicional, una técnica casi del todo abandonada por Rulfo en sus cuentos posteriores. Al examinar el cuento de cerca, sin embargo, se nota un uso hábil de este punto de vista en "La vida no es seria en sus cosas". En lugar de pensar en la perspectiva "omnisciente" más vale aplicar aquí el término que usa González Boixo cuando se refiere al narrador "equisciente" (p. 189). Es decir, se crea la impresión de que el narrador cede el paso a los pensamientos de la protagonista misma, aparentando que la perspectiva de la primera persona del singular es la que predomina. El pasaje que sigue es, en realidad, casi un monólogo introducido por la tercera persona y de repente cerrado por esa misma perspectiva intervenidera:

"Porque eso sí, tenía un miedo muy grande de que algo le sucediera a su hijo, mientras ella se la pasaba sueñe y sueñe con el otro. Y no le cabía en la cabeza sino desesperarse al no poder saber nada. Acaso sufra, se decía. Acaso se esté ahogando ahí dentro, sin aire; o tal vez tenga miedo de la obscuridad. Todos los niños se asustan cuando están a oscuras. Todos. 'Y él también. ¿Por qué no se -iba a asustar él? ¡Ah! si estuviera acá afuera, yo sabría defenderlo; o a1 menos, vería si su carita se ponía pálida o si sus ojos se hacían tristes. Entonces yo sabría como hacer. Pero ahora no; no donde él está. Ahíno. Eso se decía (pp. 154-155)".

Hasta cierto punto esta estrategia narrativa funciona bien, pero la presencia del autor es bastante obvia en el texto. Las frases "eso se decía", "esto le dijo", o "así iba el asunto" resultan ser algo intrusas. De acuerdo con la observación de Gordon, estas frases explicativas impiden que haya comunicación directa entre la protagonista y el lector (p. 21). Puede que el menosprecio de Rulfo respecto a este cuento se haya basado en este uso tentativo de la perspectiva narrativa y en el posible abuso del diminutivo sentimental cuando se refiere al feto (i.e. "su pequeño cuerpecito", "sus manitas", "su carita", "sus piernitas"). En sus cuentos posteriores se nota que "Rulfo logra soltar a los personajes para que actúen con más independencia, para que sientan las cosas y hablen por sí mismos.

La disposición de ansiedad que aumenta paulatinamente es algo que Rulfo maneja con destreza en el breve espacio textual de este cuento. Esta disposición, o este ambiente, llegó a ser un constante en sus escritos posteriores, en especial en la novela misteriosa, Pedro Páramo, donde los personajes de Comala vagan y

\footnotetext{
${ }^{2}$ Se cita a Rulfo en "Juan Rulfo pasa ...", 18.
} 
musitan en formas fantasmales. Los rasgos fundamentales de las narrativas fragmentadas de Rulfo son la ambigüedad intencional, la falta de enfoque en cl plano temporal, y una aproximación no lineal a los pensamientos y a las acciones de los personajes. En cl cuento que se examina aqui aparecen ciertas frases que confunden deliberadamente las percepciones del lector por su falta de precisión: "ahí dentro", "más de una vez", "como siempre", "algo le empujaba", etc.

La ambigüedad del caso pensado se ve también en la manera en que Rulfo delinea a los personajes. Tódos parecen fantasmas, cuando se revuelcan en sus umbas en Pedro Páramo, cuando se persiguen el "El hombre", cuando sufren del remordimiento por un fratricidio en "Talpa", o cuando se afligen por la muerte del amado en "La vida no es muy seria en sus cosas". Al pensar en la estilística de Rulfo, lo más típico, según Luis Leal, es "el aura de vaguedad que se suspende sobre la identificación de la gente y de las cosas y la indecisión de los personajes"(p. 22). Esta observación se podría extender a las acciones mismas, también, ya que el resultado final de muchos de los cuentos se deja irresuelto o simplemente implícito.

Rulfo recurre al poder de la sugestión al final de "La vida no es muy seria en sus cosas". Las consecuencias de la caída de la madre se dejan en el aire", literalmente: "Bajó muy hondo. Algo le empujaba. Debajo de ella el suelo estaba lejos, sin alcance ..." (p. 156). Esta última descripción elíptica le da una conclusión específica: las consecuencias de la caída son aniquiladoras en un nivel físico o en un nivel psicológico, si no en ambos. Al lector se le deja pensando, por un lado, en los tiernos sentimientos para con el niño por nacer. Por el otro, el lector no puede descartar la horrible posibilidad de que un enojo o una aversión por parte de la madre ante sus circunstancias haya despertado un impulso suicida/filicida, o por lo menos la ansiedad atrapada que tal impulso causa ${ }^{3}$.

No hay ninguna intención moral secundaria en "La vida no es muy seria en sus cosas", porque, como en todos sus cuentos, lo de más interés para Rulfo es tratar de los problemas relacionados a la vida diaria. Los personajes y las situaciones que presenta suelen revelarse en el plano psíquico, más que nada. Pasa muy poco, en contraste, en el plano físico. Sus cuentos carecen de anécdota central, por to general. En su lugar, Rulfo ofrece una serie de puntos de vista presentados de varias maneras. Esta multiplicidad de perspectivas revela una sensibilidad especial con respecto a la angustia humana. Rulfo explicó lo que hacía cuando escribía, diciendo lo siguiente: Mi obra no es de periodista, ni de etnólogo, ni de sociólogo. Lo que hago es una trasposición de los hechos de mi conciencia. La trasposición

${ }^{3}$ Hay una discusión extensa de tales impulsos patogénos en los capítulos "Basic Anxiety" y "Matemal Destructiveness" en Rheingold, The Mother, Anxiety and Death. 
no es una deformación, sinoel descubrimiento de formas especiales de sensibilidad (Roffe pp. 71-73). Aunque Rulfo si demuestre una sensibilidad especial en sus escritos en cuanto a los sentimientos humanos - la frustración, la culpabilidad, la soledad, la desesperación - sus textos contienen a la vez ciertas suposiciones fundamentales que sugieren que el escritor se identificaba con los arreglos tradicionales de la sociedad respecto a los sexos-o "el género" como se suele decir hoy en día. Si no estaba de acuerdo del todo con esos "arreglos", por lo menos estaba decidido a transcribirlos tal como los sentía y creía ser. "La vida no es muy seria en sus cosas" no representa, entonces, ninguna excepción en este caso. La crítica Dorothy Dinnerstein enfoca los arreglos socio-sexuales, definiendo "el malestar humano" como "una división de responsabilidad, oportunidad y privilegio, que prevalece entre el hombre y la mujer, y los patrones de interdependencia psicológica que son implícitas en esta división"'. En los últimos años, ésta y otras "lectoras resistentes" como Nancy Miller y Gilbert y Gubar han observado repetidamente que la naturaleza general de los arreglos socio-sexuales tienen su origen en un hecho central que hasta ahora ha sido predominantemente universal: el cuidado de los recién nacidos y de los niños han sido, más que nada, la responsabilidad principal de la mujer.

A algunos lectores les molestará la universalidad "antigua", si no caduca, que contiene "La vida no es muy seria en sus cosas". Sin duda alguna, Rulfo presenta la imagen de una mujer dependiente y desvalida que carece de identidad personal o de amor propio. Su protagonista está centralizada en la identidad del esposo difunto y en la del varón que cree llevar en la matriz. Se podría enfocar tal "universalidad" con otro tipo de óptica subjetiva, recordando, claro está, que la narrativa de Rulfo puede estar arraigada en una seric de prejuicios masculinos que reflejan ciertos "diseños" para con los lectores de su obra. La crítica Fetterly advierte que cualquier lector o lectora debe estar consciente de "la pretensión de que la literatura proyecta verdades universales por medio de formas de las que se han extirpado, o por lo menos transformado mediante el arte, lo representativo, todo lo meramente personal, lo puramente subjetivo"s. En efecto, aunque el texto de interés aquí sea breve, es algo chocante a veces por sus largas referencias al dolor de la madre junto con su agridulce esperanza con respecto a los hombres de su vida:

"La madre consideró la existencia de Crispín como un consuclo para ella. Todavía no descansaba de sus lágrimas; todavía había largos ratos en los cuales apretábase el recuerdo del Crispín que se le había muerto. Todavía, y esto era lo peor para

'Traducción mía del comentario de Dinnerstein, 4.

5 Traducción mía del comentario de Fetterly, ix. 
ella, no se atrevía a cantar una canción que sabía para dormir a los niños. Con todo, en ocasiones, ella le cantaba en voz baja, como para sí misma; pero enseguida, se veía rodeada por unas ganas locas de llorar, y lloraba, como sólo la ausencia de 'aquél' podía merecerlo. Luego se acariciaba su vientre y le pedía perdón a su hijo (154).

Con tal de que la realidad representada aquí por Rulfo no se transmita como la única realidad legítima, algunos lectores podrán aceptar la idea de que Rulfo, a su manera, por lo menos intenta sondear el mundo de la mujer - aunque su aproximación a ese mundo se base en un juego muy tradicional de suposiciones sobre los papeles y los sentimientos del hombre y de la mujer en la sociedad.

Puede que se aprecie mejor a Rulfo en "La vida no es muy seria en sus cosas" -más que en sus otros cuentos-por haber intentado representar la impotencia de la experiencia de su protagonista femenina. A la vez, es posible que inconscientemente haya invitado crítica negativa por dejarse participar tan abiertamente en un "discurso masculino". En este cuento no hay duda de que se ignora el efecto negativo de la narrativa sobre la imagen de sí misma de la protagonista. Hay que reconocer que no es necesariamente verídica la representación de la mujer que se hace en este texto - la de una mujer que sólo piensa en sí misma de acuerdo a sus funciones de madre y de esposa. No obstante, tampoco se puede descartar la idea de que los arreglos socio-sexuales, por injustos que sean, varian a menudo en cuanto a su naturaleza específica. Es más, estos arreglos pueden variar y cambiar de acuerdo a las condiciones particulares que predominan en cierta sociedad. Es posible que Rulfo se haya compadecido del estado lastimoso de la mujer en general, pero su representación de esé estado sugiere que como pensador lo limitaba el etnocentrismo predominante de su lugar y época.

A fin de cuentas, Rulfo sí ha intentado revelar algo del mundo interior de su protagonista femenina. Es evidente que hizo un esfuerzo por entender sus sentimientos, retratándola de una manera que no la relegara totalmente a ser una mera posesión de los hombres. En este sentido, el tema y la aproximación de Rulfo a él son algo inusitados, dada la perspectiva aún más desolada que sus escritos posteriores suelen reflejar. La novelista Elena Poniatowska, al entrevistar en una ocasión a su amigo Rulfo, le hizo el siguiente comentario: "Oye, Juan, ¿y por qué en tus cuentos y en tu novela las mujeres sólo aparecen vistas por los hombres? ... Como serás tú, Juan ... . Ninguna mujer para ti funciona como una mujer de a de veras, ninguna dice esta boca es mía ..." 'Rulfo le respondió lacónicamente a su paisana: "Es que yo tengo muy pocos personajes mujeres. Son redondas las mujeres. No tienen esquinas y no hay por dónde agarrarlas. Pues me ha costado trabajo" (161-162). Rulfo, claro está, reconocía que las mujeres representaban un enigma para él, difíciles de entender y difíciles de representar en su ficción. 
Puede que sea cierto, como implica Poniatowska, que Rulfo maltrata a las mujeres en sus textos. Hay una tendencia consistente por parte de sus personajes masculinos de tratar a las mujeres como posesiones en muchos de sus escritos: Pedro Páramo desea y manipula a la demente Susana San Juan; Lucas Lucatero se burla de la hombruña Pancha en "Anacleto Morones"; el cuñado anónimo codicia a la voluptuosa Natalia que le ayuda matar a su esposo en "Talpa". Es innegable, sin embargo, que casi todos los personajes de Rulfo reciben tratamiento negativo de alguna manera u otra. Sean hombres o mujeres, sin excepción, todos son esencialmente encarnaciones de alguna flaqueza humana específica. Ninguno de ellos funciona bien, ni mucho menos; ninguno vive de una manera completa bajo sus circunstancias. Como en otros textos de Rulfo, hay una corriente oculta de simpatía para con la protagonista de "La vida no es muy seria en sus cosas". Se asocia con ella una pérdida de identidad. Su existencia triste, su desesperación, y su desolación sirven para fragmentar aún más su identidad. El lector se inquieta, no tanto por la protagonista misma, sino por el sentido penetrante de una existencia humana desamparada, una existencia irrevocablemente condenada.

En su totalidad, "La vida no es muy seria en sus cosas" no es menos trágico que los otros cuentos desgarradores que escribió Rulfo después de este esfuerzo inicial. La preocupación central en este cuento, el primero que publicó Rulfo, fue la de tratar brevemente la imagen universal de la maternidad, una imagen especialmente sagrada en la mitología mexicana. Detrás de su protagonista anónima, la quintaesencia de la "mujer sufrida": se ven las conocidas figuras de "Nuestra Madre". Sus nombres se pronunciarán en castellano, o en maya, o en náhuatl. Serán la Virgen de los Remedios, la Virgen de Guadalupe, y Santa María, o serán Cihuacóatl y Coatlicue, diosas de la tierra, o la madre de todos los dioses, Tonantzín misma. Pero ocultándose entre todas estas figuras maternas está "la llorona", esa mítica mujer precolombina —abandonada por su marido, que mató a sus hijos. Ahora "la llorona" anda vagando por el campo mexicano, buscándolos a todos. Cree que el bulto que lleva en brazos es su niño,- y solloza al perderse en la oscuridad.

En resumidas cuentas, todos los personajes de Rulfo parecen vagar en la oscuridad, encarnaciones de ánimas en pena, - sean hombres o mujeres. Puede que su intento inicial de representar la agonía privada de una mujer no cuadre con la imagen feminista de una mujer independiente y segura de sí misma requerida por algunos lectores. Se concede que tal vez con esta imagen de "la madre sufrida" Rulfo se coloque hasta cierto punto, en otra época. Sin embargo, la actitud que se refleja para con la protagonista anónima en el tono de "La vida no es muy seria en sus cosas" es, más que nada, una actitud de simpatía, y no de ninguna condescendencia barata. Cuando se toma la obra de Rulfo en su totalidad, es evidente que el 
maestro mexicano toma un nuevo camino dentro de su territorio literario con este cuento "olvidado". Juan Rulfo proyecta un rayito de luz sobre la primera de muchas figuras umbrias que poblarán el pavoroso mundo de su narrativa subsecuente, esos seres llenos de imperfecciones y de tan poca esperanza, esa gente melancólica predestinada a la destrucción y al olvido. 


\section{OBRAS CITADAS}

Acker, Bertie. El cuento mexicano contemporáneo: Rulfo, Arreola y Fuentes. Madrid: Editorial Playor, 1984.

Carballido, Emilio. Los narradores ante el público. México: Joaquín Mortiz, 1966.

Dinnerstein, Dorothy. The Mermaid and the Minotaur: Sexual Arrangements and the Human Malaise. New York: Harper and Row, 1976.

Durán, Manuel. Triptico mexicano: Rulfo, Fuentes, Elizondo. México: Secretaría de Educación Pública, 1973.

Fetterly, Judith. The Resisting Reader: A Feminist Approach to American Fiction.. Bloomington and London: Indiana University Press, 1977.

González Boixo, José. Claves narrativas de Juan Rulfo. León, España: Colegio Universitario de Lcón, 1980.

Gordon, Donàld K. Los cuentos de Juan Rulfo. Madrid: Editorial Playor, 1976.

"Juan Rulfo pasa a la historia con 250 páginas", El país. 9 de enero, 1986: 18.

Leal, Luis. Juan Rulfo. Boston, Twayne, 1983.

Poniatowska, Elena. ¡Ay vida, no me mereces! Joaquín Mortiz, 1983.

Rheingold, Joseph C. The Mother, Anxiety and Death. London: Litle, Brown and Co., 1967.

Rodríguez Alcalá, Hugo. El arte de Juan Rulfo. México: Instituto Nacional de Bellas Artes, 1965.

Roffe, Reina, ed. Juan Rulfo: Autobiografía armada. Buenos Aires, Ediciones Corregidor, 1973.

Ruffinelli, Jorge. "Prólogo" in Rulfo, Antología personal. 
Rulfo, Juan. El gallo de oroy otros textos para cine. México: Ediciones Era, 1980. . "La vida no es muy seria en sus cosas", en Antología personal. México: Nueva Imagen, 1978: 153-156. . "Pedro Páramo, 30 años después", El país, 13 de enero, 1986: 18-19.

Sommers, Joseph. After the Storm: Landmarks of the Modern Mexican Novel. Albuquerque: University of New Mexico Press, 1986.

Verdugo, Iber H. Un estudio de la narrativa de Juan Rulfo. México: UNAM, 1982. 